\begin{abstract}
myFMH - die Internetplattform für FMH-Mitglieder ist auf der FMH-Website www.fmh.ch aufgeschaltet!

Letzte Woche haben 200 Ärztinnen und Ärzte, die nach dem Zufallsprinzip ausgewählt wurden, ihre Registrierungsunterlagen erhalten. Im Laufe des Monats Juni 2006 werden nach und nach alle FMH-Mitglieder die Unterlagen für die Registrierung - FMH-ID und Registrierungsschlüssel - per Post zugestellt erhalten. Ohne Registrierung kann über die Schaltfläche myFMH nur die Infoseite konsultiert werden. Bei Schwierigkeiten mit der Registrierung erhalten Sie Hilfe über die speziell eingerichtete Helpline: Tel. 0313591259 oder E-Mail an info-dig@fmh.ch.
\end{abstract}

\title{
myFMH - le portail internet pour les membres de la FMH - est installé sur le site internet de la FMH www.fmh.ch!
}

La semaine dernière, 200 médecins choisis au hasard ont reçu leurs documents d'enregistrement. Ces mêmes documents, qui contiennent l'identification FMH et une clé d'enregistrement, seront envoyés par courrier postal à tous les membres de la FMH dans le courant du mois de juin 2006. Sans enregistrement, I'accès au portail myFMH est limité à la page d'information. Si vous rencontrez des difficultés lors de votre enregistrement, vous obtiendrez de l'aide par la ligne d'assistance téléphonique spécialement installée à cet effet, au no 03135912 59, ou par e-mail à info-dig@fmh.ch. 